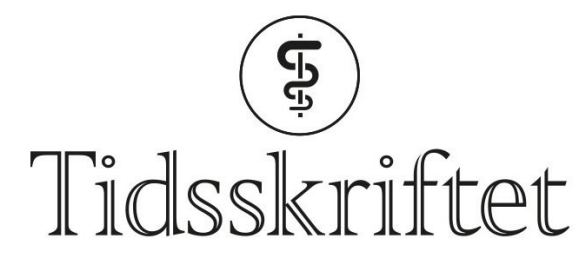

DEN NORSKE LEGEFORENING

\title{
Akutt forgiftning med gammahydroksybutyrat
}

KORT RAPPORT

\section{ARON C. ARONSEN}

Medisinsk fakultet

Universitetet i Oslo

Aron C. Aronsen er vernepliktig lege i Forsvaret.

Forfatteren har fylt ut ICMJE-skjemaet og oppgir ingen interessekonflikter.

\section{METTE BREKKE}

Allmennmedisinsk forskningsenhet

Universitetet i Oslo

Mette Brekke er spesialist i allmennmedisin og professor.

Forfatteren har fylt ut ICMJE-skjemaet og oppgir ingen interessekonflikter.

\section{ODD MARTIN VALLERSNES}

E-post: o.m.vallersnes@medisin.uio.no

Avdeling for allmennmedisin

Universitetet i Oslo

og

Legevakten i Oslo, Allmennlegevakten

Oslo kommune, Helseetaten

Odd Martin Vallersnes er spesialist i allmennmedisin, førsteamanuensis og legeskiftleder.

Forfatteren har fylt ut ICMJE-skjemaet og oppgir ingen interessekonflikter.

\section{BAKGRUNN}

Mange pasienter med forgiftning med gammahydroksybutyrat (GHB) behandles i Oslo på legevaktnivå. Vi beskriver klinisk bilde ved GHB-forgiftning og sammenlikner sykehusinnlagte med pasienter som ble ferdigbehandlet ved Legevakten i Oslo.

\section{MATERIALE OG METODE}

Vi registrerte retrospektivt alle pasienter med klinisk diagnostisert GHB-forgiftning ved Legevakten i Oslo fra 1.10.2013 til 30.9.2015. Vi inkluderte kun tilfeller der GHB var tatt i rusøyemed. 


\section{RESULTATER}

Vi fant 329 tilfeller av GHB-forgiftning i perioden. Median alder var 30 år (interkvartilområde 25-36 år, spenn 15-56 år), og 228 (69\%) av tilfellene var menn. GHB var tatt som eneste rusmiddel i 128 (39\%) tilfeller, kombinert med alkohol i 96 (29\%) og med amfetamin i 65 (20\%). Nedsatt bevissthet ble observert i 218 (69\%) tilfeller, koma (Glasgow Coma Scale-skår $\leq 7)$ i $43(14 \%)$ og agitasjon i 117 (36\%). Sammenliknet med pasienter ferdigbehandlet på legevakten var de 159 (48\%) sykehusinnlagte pasientene oftere komatøse ( $23 \%$ vs. $5 \%, \mathrm{p}<0,001)$ og agiterte ( $43 \%$ vs. $28 \%, \mathrm{p}=0,008)$. Median observasjonstid på legevakt før innleggelse var 42 min (interkvartilområde 26 min-1 t 23 min, spenn 2 min-2o t 10 min) vs. 3 t 1 min (interkvartilområde 1 t 32 min-4 t 42 min, spenn 14 min-15t $37 \mathrm{~min})$ for de som ble ferdigbehandlet på legevakten $(\mathrm{p}<\mathrm{o}, 001)$.

\section{FORTOLKNING}

Halvparten av pasientene med GHB-forgiftning ble ferdigbehandlet på legevaktnivå. Mange av de sykehusinnlagte hadde alvorlige symptomer som raskt krevde innleggelse.

Gammahydroksybutyrat (GHB) og de nære slektningene gammabutyrolakton (GBL) og 1,4butandiol (BD) er forholdsvis nye rusmidler i Norge. De dukket først opp i 1980-årene (1). I 2014 oppga 1,7 \% i aldersgruppen 16-30 år å ha brukt GHB én eller flere ganger (2). Ved Legevakten i Oslo økte antallet GHB-forgiftninger med 148 \% fra 2008 til 2012 (3).

Som rusmiddel inntas GHB, GBL og BD hovedsakelig peroralt i væskeform (1). GBL og BD omdannes til GHB i kroppen. GHB har en doseavhengig sentraldempende effekt og gir i lave doser eufori, forvirring, svimmelhet og somnolens. Effektene inntrer 15-20 minutter etter inntak og varer i 2-4 timer, fulgt av rask oppvåkning. Maksimal effekt nås etter 30-6o minutter. Den bratte dose-respons-kurven gjør at det er liten forskjell på en rusgivende dose og en overdose $(4,5)$.

GHB-forgiftning kan gi svekket respirasjon, bradykardi, hypotensjon, hukommelsestap, nedsatt og ofte vekslende bevissthetsnivå, agitasjon, kramper og koma. Særlig farlig er kombinasjon med andre sentraldempende midler som virker synergistisk med GHB $(4,5)$. Dødsfall forekommer (3-4 i året i Norge (6)), og skyldes vanligvis respirasjonsstans.

Behandlingen er adekvate støttetiltak med overvåkning av respirasjon og sirkulasjon. Viktigst er fri luftvei og respirasjonsstøtte om nødvendig. Agitasjon kan medføre behov for sedasjon i form av benzodiazepiner, eventuelt narkose og intubasjon. Det finnes ikke antidot. Agitasjon ses også ved abstinens, som kan inntreffe få timer etter siste inntak (5).

Sykehusinnleggelse er ofte nødvendig ved GHB-forgiftning, men i Oslo blir mange behandlet på legevakten. Formålet med denne studien er å beskrive klinisk bilde, behandling og enkle demografiske data for pasienter som behandles for GHB-forgiftning på Legevakten i Oslo, og å sammenlikne pasientene som ble ferdigbehandlet der, med de som ble sendt videre til sykehus.

\section{Materiale og metode}

Studien er en observasjonell, retrospektiv studie. Vi brukte registreringsskjemaet og variabelsettet utviklet av det europeiske forskningsnettverket The European Drug Emergencies Network (Euro-DEN) (7).

Vi inkluderte alle pasienter behandlet for GHB-forgiftning ved Legevakten i Oslo fra 1.10.2013 til 30.9.2015. Vi inkluderte kun tilfeller der GHB var tatt i rusøyemed, ikke forgiftninger med suicidal intensjon eller forgiftninger påført av andre. Diagnosen av inntatte rusmidler bygget på vurderingen journalført av behandlende lege, som igjen var basert på klinisk undersøkelse og opplysninger fra pasient og komparenter. Det ble ikke utført laboratoriediagnostikk. Pasientene ble funnet ved gjennomgang av problemstillingene 
registrert ved innkomst i innskrivingslistene i legevaktens elektroniske journalsystem.

De fleste pasienter med rusmiddelforgiftning i Oslo behandles ved legevakten etter en standardisert prosedyre med enkle midler (8). Pasienter som trenger mer avansert diagnostikk eller behandling, sendes videre til sykehus.

Data ble samlet fra elektroniske journalnotater og fra observasjonsskjemaet som brukes ved antatt rusmiddelforgiftning. Vi registrerte alder, kjønn, innkomsttid, innkomstmåte, inntatte rusmidler, gitt behandling, observasjonstid (fra ankomst til pasienten forlot legevakten) og videre tiltak samt et sett av kliniske symptomer og funn.

Studien ble gjort som et kvalitetssikringsprosjekt. Prosjektet er vurdert av personvernombudet ved Oslo universitetssykehus.

Statistiske analyser ble gjort i SPSS versjon 25. Data beskrives med median, interkvartilområde og spenn. I sammenlikningen av sykehusinnlagte og ikke-

sykehusinnlagte pasienter ble khikvadrattest og Fishers eksakte test brukt for andeler og Mann-Whitneys U-test for kontinuerlige variabler.

\section{Resultater}

Blant totalt 329 tilfeller av GHB-forgiftning var 101 (31\%) kvinner (tabell 1). Median alder var 30 år (interkvartilområde 25-36 år, spenn 15-56 år).

\section{Tabell 1}

Forgiftninger med gammahydroksybutyrat (GHB) behandlet ved Legevakten i Oslo fra 1.10.2013 til 30.9.2015. Pasientkarakteristika, behandling og tiltak som antall (\%) dersom annet ikke er angitt.

\begin{tabular}{|c|c|c|c|}
\hline & $\begin{array}{r}\text { GHB eneste } \\
\text { agens }\end{array}$ & $\begin{array}{r}\text { GHB og } \\
\text { tilleggsagens }\end{array}$ & Totalt \\
\hline \multicolumn{4}{|l|}{ Kjønn } \\
\hline Menn & $87(68)$ & $141(70)$ & $228(69)$ \\
\hline Kvinner & $41(32)$ & $60(30)$ & $101(31)$ \\
\hline $\begin{array}{l}\text { Alder (år), median } \\
\text { (interkvartilområde) }\end{array}$ & $31(27-36)$ & $29(25-35)$ & $30(25-36)$ \\
\hline Brakt av ambulanse & $42(33)$ & $107(53)$ & $149(45)$ \\
\hline $\begin{array}{l}\text { Behandling utover kun } \\
\text { observasjon }\end{array}$ & $13(10)$ & $29(14)$ & $42(13)$ \\
\hline Intubasjon & $1(1)$ & & $1(<0,5)$ \\
\hline Nalokson (antidot mot opioider) ${ }^{2}$ & $8(6)$ & $21(10)$ & $29(9)$ \\
\hline $\begin{array}{l}\text { Flumazenil (antidot mot } \\
\text { benzodiazepiner) }\end{array}$ & - & $1(<0,5)$ & $1(<0,5)$ \\
\hline Sedasjon $^{2}$ & $3(2)$ & $2(1)$ & $5(2)$ \\
\hline $\begin{array}{l}\text { Observasjonstid (timer:minutter), } \\
\text { median (interkvartilområde) }\end{array}$ & $0: 48(0: 28-2: 15)$ & $2: 02(0: 57-3: 56)$ & $1: 28(0: 38-3: 17)$ \\
\hline \multicolumn{4}{|l|}{ Videre tiltak } \\
\hline Innlagt sykehus & $82(64)$ & $78(39)$ & $160(49)$ \\
\hline $\begin{array}{l}\text { Ferdig behandlet ved } \\
\text { legevakt }\end{array}$ & $34(27)$ & $96(48)$ & $130(40)$ \\
\hline $\begin{array}{l}\text { Forlot legevakten under } \\
\text { behandling }\end{array}$ & $12(9)$ & 27 (13) & $39(12)$ \\
\hline Totalt & $128(100)$ & $201(100)$ & $329(100)$ \\
\hline
\end{tabular}

${ }^{1}$ Manglende data for 19 tilfeller.

${ }^{2}$ Gitt ved legevakten og/eller i ambulanse før ankomst legevakt.

I 128 (39\%) av tilfellene var GHB oppgitt å være eneste rusmiddel. I de resterende var GHB 
inntatt sammen med ett eller flere andre rusmidler: etanol i 96 (29\%) tilfeller, amfetamin i $65(20 \%)$, benzodiazepiner i $49(15 \%)$, heroin i $46(14 \%)$, cannabis i $14(4 \%)$ og kokain i 12 $(4 \%)$.

Det mest framtredende kliniske funnet var nedsatt bevissthet. 218 (69\%) hadde GCS-skår (Glasgow Coma Scale) < 15, og 43 (14\%) var i koma (GCS-skår $\leq 7$ ), mens 117 (36\%) var agiterte (tabell 2). Av 43 som var i koma ved ankomst, ble 11 (26\%) agiterte i forløpet. Det samme ble 59 av 175 (34\%) pasienter som hadde GCS-skår 8-14 ved ankomst.

\section{Tabell 2}

Klinisk bilde ved forgiftning med gammahydroksybutyrat (GHB) behandlet ved Legevakten i Oslo fra 1.10.2013 til 30.9.2015. Antall (\%).

\begin{tabular}{|c|c|c|c|}
\hline & $\begin{array}{r}\text { GHB eneste } \\
\text { agens }\end{array}$ & $\begin{array}{r}\text { GHB og } \\
\text { tilleggsagens }\end{array}$ & Totalt \\
\hline \multicolumn{4}{|l|}{$\begin{array}{l}\text { Bevissthetsnivå, Glasgow Coma Scale- } \\
\text { skårr }\end{array}$} \\
\hline 15 & $29(25)$ & $71(36)$ & $100(31)$ \\
\hline $8-14$ & $69(58)$ & $106(53)$ & $175(55)$ \\
\hline$\leq 7$ & 20 (17) & $23(12)$ & $43(14)$ \\
\hline $\begin{array}{l}\text { Bradypné (respirasjonsfrekvens < } \\
12 \text { pust/min) }\end{array}$ & $6(5)$ & 19 (9) & $25(8)$ \\
\hline $\begin{array}{l}\text { Takypné (respirasjonsfrekvens } \geq \\
20 \text { pust } / \mathrm{min})^{1}\end{array}$ & $20(16)$ & $37(18)$ & $57(17)$ \\
\hline Bradykardi (puls $<50$ slag $/ \mathrm{min})^{1}$ & $4(3)$ & $7(3)$ & $11(3)$ \\
\hline Takykardi (puls $\geq 100 \mathrm{slag} / \mathrm{min})^{1}$ & $13(10)$ & $49(24)$ & $62(19)$ \\
\hline $\begin{array}{l}\text { Hypotensjon (systolisk blodtrykk } \leq \\
90 \mathrm{~mm} \mathrm{Hg} \text { ) }\end{array}$ & $4(3)$ & $6(3)$ & $10(3)$ \\
\hline Hypertermi (temperatur $\geq 39^{\circ} \mathrm{C}$ ) & - & - & \\
\hline Oppkast & $5(4)$ & $10(5)$ & $15(5)$ \\
\hline Hodepine & - & $6(3)$ & $6(2)$ \\
\hline Angst & $8(6)$ & $13(6)$ & $21(6)$ \\
\hline Hallusinasjoner & $3(2)$ & $5(2)$ & $8(2)$ \\
\hline Agitasjon & $55(43)$ & $62(31)$ & $117(36)$ \\
\hline Psykose & $2(2)$ & $3(1)$ & $5(2)$ \\
\hline Kramper & $3(2)$ & $7(3)$ & $10(3)$ \\
\hline Totalt & $128(100)$ & $201(100)$ & $329(100)$ \\
\hline
\end{tabular}

${ }^{\mathrm{I}}$ Ved innkomst.

${ }^{2}$ Manglende data for 11 tilfeller, $\mathrm{n}=118$ for GHB eneste agens og $\mathrm{n}=\mathbf{2 0 0}$ for GHB og tilleggsagens.

Pasienten ble innlagt i somatisk sykehus i 159 (48\%) tilfeller (tabell 1). Median observasjonstid på legevakten var 1 t 28 min (interkvartilområde 38 min-3 t 17 min, spenn 2 min-2o t $10 \mathrm{~min}$ ). Observasjonstiden var kortere når den endte med innleggelse: $42 \mathrm{~min}$ med innleggelse (interkvartilområde 26 min-1 time 23 min, spenn 2 min-2o t 10 min) vs. $3 \mathrm{t}$ 1 min uten (interkvartilområde $1 \mathrm{t} 32$ min-4 t 42 min, spenn 14 min -15 t 37 min) $(p<0,001)$. Innlagte pasienter hadde oftere GCS-skår $\leq 7$ ( $23 \%$ vs. $5 \%$; p < o,oo1) og var oftere agiterte ( $43 \%$ vs. $28 \%$; p = o,oo8). Utover dette skilte ikke de innlagte pasientene seg fra de øvrige. Ingen pasienter døde på legevakten.

\section{Diskusjon}

Den kraftige økningen i antallet GHB-forgiftninger behandlet på legevaktnivå i Oslo fra 2008 til 2012 fortsatte ikke i vår studieperiode fram til 2015 (3), men stabiliserte seg på rundt 150 tilfeller per år. 
Nedsatt bevissthet og agitasjon preget som forventet det kliniske bildet $(4,5)$, og mange var både komatøse og agiterte. Takypné og takykardi var også utbredt og har trolig

sammenheng med agitasjon eller samtidig inntak av rusmidler med stimulerende effekter, f.eks. amfetamin eller kokain. Ofte er pasienter med GHB-forgiftning så agiterte at sedasjon er nødvendig. På grunn av risikoen for å potensere den respirasjonsdempende effekten av GHB legges pasienten da inn på sykehus, der sedasjon kan gis i mer kontrollerte former enn på legevakt, med bedre muligheter for overvåkning og respirasjonsstøtte.

Sedasjonskrevende agitasjon er dermed en hovedgrunn for sykehusinnleggelse ved GHBforgiftning. Koma er en annen fordi det kan ledsages av respirasjonsdepresjon, noe vi så hos $8 \%$. Vi vet ikke når i forløpet pasientene i vårt materiale var agiterte, bare at de var det, men vekslingen mellom agitasjon og koma er vanskelig å håndtere på legevakt. Så mange som halvparten av pasientene med GHB-forgiftning ble lagt inn på sykehus, til forskjell fra $17 \%$ av pasientene med rusmiddelforgiftning generelt ved Legevakten i Oslo $(8,9)$. Flere av de innlagte pasientene i vårt materiale var verken komatøse eller agiterte, og man kunne dermed tenke at flere av dem kunne ha blitt ferdigbehandlet på legevaktnivå. Imidlertid har vi kun registrert skår på Glasgow Coma Scale ved ankomst, og vi vet dermed ikke om de innlagte pasientene hadde fallende bevissthetsnivå i forløpet. Fallende bevissthetsnivå kan følges av respirasjonsdepresjon og bør derfor medføre sykehusinnleggelse. Dess lengre vei til sykehuset, dess tidligere bør man handle.

\section{STYRKER OG SVAKHETER}

Vår studie søkte å omfatte alle pasienter med antatt GHB-forgiftning behandlet på legevaktnivå i Oslo i en toårsperiode. Det retrospektive designet medfører fare for at vi kan ha oversett noen, men vi kan ikke se at dette skulle forårsake systematiske skjevheter. Imidlertid bringes de alvorligste GHB-forgiftningene direkte til sykehus av ambulansetjenesten, og i 2012 utgjorde dette like mange som de som ble innlagt fra legevakten $(9,10)$. Siden de dårligste pasientene ikke kommer til legevakten, reflekterer ikke våre funn alvorlighetsgraden av GHB-forgiftninger totalt sett. Likevel mener vi at våre funn har klinisk relevans for andre legevakter med observasjonsmulighet og for sykehusakuttmottak på steder der rusmiddelforgiftede pasienter ikke behandles på legevakt.

Laboratorieanalyser for påvisning av rusmidler ble ikke utført. Dette medfører usikkerhet om hvilke agens pasientene hadde inntatt. Imidlertid er agensregistreringen vår basert på den kliniske vurderingen som ble gjort der og da, og som styrte behandlingen pasienten fikk.

Våre data er fem år gamle, og siden da kan GHB-brukergruppen ha endret seg. Panoramaet av tilleggsrusmidler kan også ha endret seg.

\section{Konklusjon}

Pasienter med antatt GHB-forgiftning innkom ofte med redusert bevissthetsnivå og agitasjon. Halvparten av pasientene ble sendt videre til sykehus. Framtidig forskning bør lete etter indikatorer for når sykehusinnleggelse er nødvendig, og når det er trygt å behandle på legevakt.

\section{HOVEDFUNN}

Vekslende bevissthetsnivå og agitasjon var hyppige funn hos pasienter behandlet for antatt GHB-forgiftning på Legevakten i Oslo.

Halvparten av pasientene ble sendt videre til sykehus. 
1. Bramness JG, Haugland S. Misbruk av gammahydroksybutyrat. Tidsskr Nor Legeforen 2011; 131: 2122-5. [PubMed][CrossRef]

2. Sandøy TA. Bruk av illegale rusmidler: resultater fra befolkningsundersøkelser 2012-14. Oslo: Statens institutt for rusmiddelforskning, 2015. https://www.fhi.no/publ/2015/bruk-av-illegale-rusmidler/ Lest 7.5.2020.

3. Vallersnes OM, Jacobsen D, Ekeberg $\emptyset$ et al. Patients presenting with acute poisoning to an outpatient emergency clinic: a one-year observational study in Oslo, Norway. BMC Emerg Med 2015; 15: 18. [PubMed][CrossRef]

4. Busardò FP, Jones AW. GHB pharmacology and toxicology: acute intoxication, concentrations in blood and urine in forensic cases and treatment of the withdrawal syndrome. Curr Neuropharmacol 2015; 13: 47-70. [PubMed][CrossRef]

5. Schep LJ, Knudsen K, Slaughter RJ et al. The clinical toxicology of $\gamma$-hydroxybutyrate, $\gamma$-butyrolactone and 1,4-butanediol. Clin Toxicol (Phila) 2012; 50: 458-70. [PubMed][CrossRef]

6. Simonsen KW, Edvardsen HM, Thelander G et al. Fatal poisoning in drug addicts in the Nordic countries in 2012. Forensic Sci Int 2015; 248: 172-8o. [PubMed][CrossRef]

7. Wood DM, Heyerdahl F, Yates CB et al. The European Drug Emergencies Network (Euro-DEN). Clin Toxicol (Phila) 2014; 52: 239-41. [PubMed][CrossRef]

8. Vallersnes OM, Jacobsen D, Ekeberg $\emptyset$ et al. Outpatient treatment of acute poisoning by substances of abuse: a prospective observational cohort study. Scand J Trauma Resusc Emerg Med 2016; 24 : 76. [PubMed][CrossRef]

9. Lund C, Vallersnes OM, Jacobsen D et al. Outpatient treatment of acute poisonings in Oslo: poisoning pattern, factors associated with hospitalization, and mortality. Scand J Trauma Resusc Emerg Med 2012; 20: 1. [PubMed][CrossRef]

10. Lund C, Teige B, Drottning P et al. A one-year observational study of all hospitalized and fatal acute poisonings in Oslo: epidemiology, intention and follow-up. BMC Public Health 2012; 12: 858.

[PubMed][CrossRef]

Publisert: 29. juni 2020. Tidsskr Nor Legeforen. DOI: 10.4045/tidsskr.19.078o

Mottatt 2.12.2019, første revisjon innsendt 5.3.2020, godkjent 7.5.2020.

(C) Tidsskrift for Den norske legeforening 2020. Lastet ned fra tidsskriftet.no 